\title{
Non-Darcian effects on natural convection in porous media confined between horizontal cylinders
}

\author{
M. KAVIANY \\ Department of Mechanical Engineering and Applied Mechanics, University of Michigan, Ann Arbor. \\ MI 48109, U.S.A.
}

(Received 7 October 1985 and in final form 21 April 1986)

\begin{abstract}
The inertia, boundary and velocity-square terms, normally not included in the flow analysis, are included in the study of natural convection between isothermal, concentric cylinders (inner cylinder heated) filled with saturated, porous media. The results show that all of these effects reduce the heat transfer rate with the boundary term being the most significant. It is shown that since at high Rayleigh numbers the flow adjacent to the confining walls becomes of boundary-layer type, with a very thin sublayer over which the velocity reaches its maximum value, then as long as the contribution of the velocity-square term is small, Darcy's model holds for very large Rayleigh and Prandtl numbers. A flow regime diagram showing the pseudo-conduction, Darcy and non-Darcy regimes, is given.
\end{abstract}

\section{INTRODUCTION}

FLuID flow in saturated, porous media with high permeabilities manifests some of the characteristics of the flow in the absence of a rigid matrix, i.e. the inertia and boundary effects not included in Darcy's model may become significant [1-4]. Also, at high velocities the rigid matrix resistance is no longer given by Darcy's law, i.e. the velocity-square term becomes significant [5]. The inertia or development term which may be significant in the leading edge region (external flows) [1-3] and in the entrance region (internal flows) [4] becomes less significant in the presence of a solid matrix because the lower the permeability the shorter is the development region $[1,3,4]$. This is due to the proportionality of the flow resistance to the local velocity which tends to make the velocity field uniform. In boundary-layer flows, the relative influence of the boundary term on the heat transfer rate is manifested in the ratio of the thermal to momentum boundary-layer thickness $[1,3,4]$. In general, for a given flow driving force (pressure gradient or buoyancy) the results have shown that each of the three effects, i.e. inertia, boundary and velocity-square, reduces the heat transfer rate.

In natural convection between isothermal, horizontal cylinders-as in other enclosure convections-as the buoyancy potential (Rayleigh number) increases, three regimes are observed. First is the regime of no significant convection, i.e. conduction regime, then the non-boundary-layer convection or the conduction-convection regime is observed. Finally the boundary-layer flow regime is reached. At still higher Rayleigh numbers the flow becomes unstable and various transitions have been observed. Convection between isothermal, horizontal cylinders has been studied in detail in the presence of a rigid matrix in Darcy's regime [6-9] and also in the absence of any rigid matrix $[10,11]$. It is found that when no rigid matrix is present, and for air, unsteady threedimensional flows begin above $R a=3 \times 10^{6}$ and $10^{5}$ for $R=2$ and 4, respectively [11], where $R$ is the diameter ratio and $R a$ is the Rayleigh number. When the solid matrix is present and Darcy's law holds, it is found that for $R=2$ and $R a \gamma^{-2}$ greater than 134 , unsteady three-dimensional convection will take place [6], where $\gamma^{2}$ is proportional to the inverse of the permeability.

In this study, the non-Darcy effects on natural convection between two concentric, isothermal, horizontal cylinders (inner cylinder heated) filled with a fluid-saturated, porous medium, are studied by solving the two-dimensional conservation equations numerically. Some of the $R a$ and $R a \gamma^{-2}$ values considered in this study are larger than the critical values given above for very small and very large permeabilities. However, since no definite statement can yet be made for moderate permeabilities the numerical results are assumed to be for stable flows. Figure 1 gives a schematic of the problem considered.

\section{ANALYSIS}

Assuming local thermal equilibrium between the solid and fluid, and also, a Boussinesq fluid, the conservation equations based on the available empirical data and the volume average principles [1] are

$$
\begin{gathered}
\nabla \cdot \mathbf{u}=0 \\
(\mathbf{u} \cdot \nabla) \mathbf{u}=-\rho_{\mathrm{o}}^{-1} \nabla p+\rho \rho_{\mathrm{o}}^{-1} g \mathbf{k}+\nu \nabla^{2} \mathbf{u} \\
-K^{-1} \varepsilon v \mathbf{u}-F \varepsilon^{2} K^{-1 / 2}|\mathbf{u}| \mathbf{u} \\
(\mathbf{u} \cdot \nabla) T=\alpha_{\mathrm{e}} \nabla^{2} T
\end{gathered}
$$

where equation (2) allows for the Darcy resistance as 


\section{NOMENCLATURE}

\begin{tabular}{|c|c|c|c|}
\hline$D$ & diameter $[\mathrm{m}]$ & $\gamma$ & dimensionless porous media shape \\
\hline$F$ & empirical constant & & parameter (ratio of large to small \\
\hline$g$ & gravitational constant $\left[\mathrm{m} \mathrm{s}^{-2}\right]$ & & length scale) $\left(\epsilon D_{\mathrm{i}} / K\right)^{1 / 2}$ \\
\hline$K$ & permeability $\left[\mathrm{m}^{2}\right]$ & $\varepsilon$ & porosity \\
\hline$p$ & pressure $\left[\mathrm{N} \mathrm{m}^{-2}\right]$ & $y$ & kinematic viscosity $\left[\mathrm{m}^{2} \mathrm{~s}^{-1}\right]$ \\
\hline $\mathrm{Pr}$ & effective Prandtl number, $v / \alpha_{e}$ & $\phi$ & azimuthal angle [rad] \\
\hline$r$ & radial position $[\mathrm{m}]$ & $\phi$ & unit vector \\
\hline $\mathbf{r}$ & unit vector & $\psi$ & streamfunction $\left[\mathrm{m}^{2} \mathrm{~s}^{-2}\right]$ \\
\hline$R$ & $\begin{array}{l}\text { ratio of outside to inside diameter, } \\
D_{\mathrm{o}} / D_{\mathrm{i}}\end{array}$ & $\Psi$ & $\begin{array}{l}\text { dimensionless second-order resistance } \\
\text { due to the presence of the solid }\end{array}$ \\
\hline$R a$ & Rayleigh number, $g \beta\left(T_{i}-T_{0}\right) D_{i}^{3} / v \alpha_{e}$ & & matrix, $F \varepsilon^{2} D_{\mathrm{i}} / K^{1 / 2}$ \\
\hline$T$ & temperature $\left[{ }^{\circ} \mathrm{C}\right]$ & $\omega$ & vorticity $\left[\mathrm{s}^{-1}\right]$ \\
\hline$\Delta T$ & $T_{i}-T_{0}\left[{ }^{\circ} \mathrm{C}\right]$ & \multicolumn{2}{|c|}{ Superscript } \\
\hline$u$ & $r$-direction velocity $\left[\mathrm{m} \mathrm{s}^{-1}\right]$ & $*$ & dimensional. \\
\hline$v$ & $\phi$-direction velocity $\left[\mathrm{m} \mathrm{s}^{-1}\right]$ & \multicolumn{2}{|l|}{ Subscripts } \\
\hline & & $\mathrm{i}$ & inside \\
\hline \multicolumn{2}{|c|}{ Ireek symbols } & $\max$ & maximum \\
\hline$\alpha_{\mathrm{e}}$ & effective thermal diffusivity $\left[\mathrm{m}^{2} \mathrm{~s}^{-1}\right]$ & o & outside \\
\hline$\beta$ & thermal expansion coefficient $\left[{ }^{\circ} \mathrm{C}\right]$ & $r, \phi$ & $r$ and $\phi$ derivatives. \\
\hline
\end{tabular}

well as for the second-order resistance found for pore Reynolds numbers larger than unity [5]. However, these equations do not account for any dispersion or spreading of momentum and thermal energy due to inter-pore mixing in the presence of a velocity gradient. This effect which is only significant at relatively high velocities and for large gradients, is discussed in ref. [12]. For the present problem these equations can reasonably describe the phenomena.

The above equations have been nondimensionalized using:

$$
r^{*}=\frac{r}{D_{i}}, \quad u^{*}=\frac{u D_{i}}{\alpha_{\mathrm{e}}} \quad \text { and } \quad T^{*}=\frac{T-T_{\mathrm{o}}}{T_{i}-T_{0}}
$$

in the following all the quantities are dimensionless and the asterisks are dropped for convenience.

Introducing the streamfunction $\left(r^{-1} \psi_{\phi}=u\right.$ and $\left.\psi_{r}=-v\right)$ and vorticity $(\omega=\nabla \times u)$, we arrive at the following vorticity equation by taking the curl of equation (2)

$$
\begin{aligned}
\operatorname{Pr}^{-1} r^{-1}\left(\psi_{\phi} \omega_{r}-\psi_{r} \omega_{\phi}\right) & \\
= & \nabla^{2} \omega-\operatorname{Ra}\left(r^{-1} \cos \phi T_{\phi}+\sin \phi T_{r}\right) \\
& -\gamma^{2} \omega+\Psi\left[r^{-1}\left(r|\mathbf{u}| \psi_{r}\right)_{r}\right. \\
& \left.+r^{-2}\left(|\mathbf{u}| \psi_{\phi}\right)_{\phi}\right] .
\end{aligned}
$$

We also have

$$
\begin{gathered}
\nabla^{2} \psi=-\omega \\
r^{-1}\left(\psi_{\phi} T_{r}-\psi_{r} T_{\phi}\right)=\nabla^{2} T .
\end{gathered}
$$

The emerging dimensionless parameters are:

$$
\begin{gathered}
R=\frac{D_{\mathrm{o}}}{D_{\mathrm{i}}}, \quad R a=\frac{g \beta\left(T_{\mathrm{i}}-T_{\mathrm{o}}\right) D_{\mathrm{i}}^{3}}{\alpha_{\mathrm{e}} \nu} \\
\gamma^{2}=\frac{\varepsilon D_{\mathrm{i}}^{2}}{K}, \quad \Psi=\frac{F \varepsilon^{2} D_{\mathrm{i}}}{K^{1 / 2}}, \quad \operatorname{Pr}=\frac{\nu}{\alpha_{\mathrm{e}}} .
\end{gathered}
$$

The physical significance of these parameters are:

(a) the relative buoyancy potential given by the Rayleigh number $R a$;

(b) the relative significance of the inertia term given by the Prandtl number $P r$;

(c) the first-order rigid matrix resistance given by the porous media shape parameter $\gamma$, which is the ratio of the large length scale (taken to be the curvature instead of the gap spacing) to small length scale; and

(d) second-order rigid matrix resistance given by $\Psi$

The boundary conditions are (also shown in Fig. 1)

$$
\begin{array}{lll}
\text { at } & r=0.5 & \psi=0, T=1, \omega=-\psi_{r r} \\
\text { at } \quad r=R / 2 & \psi=0, T=0, \omega=-\psi_{r r} \\
\text { at } \quad \phi=0, \pi & \psi=0, T_{\phi}=0, \omega=0
\end{array}
$$

where $R$ is the ratio of the outside to inside diameter.

\section{SOLUTION AND VALIDATION}

Equations (4)-(6) subject to equations (7)-(9) are solved numerically using the finite-difference approximations (hybrid method [13]), a uniform grid 


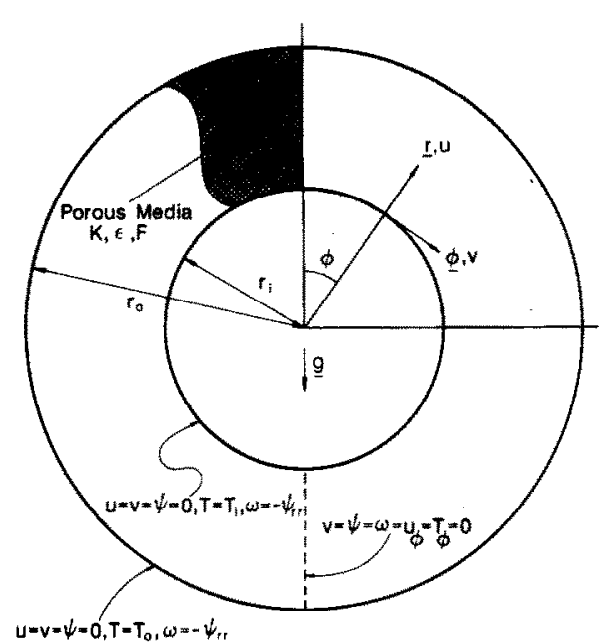

FIG. 1. A schematic of the problem considered.

net and the relaxation technique. The convergence criterion was that the change in the normalized value of the streamfunction between any two successive iterations be less than $10^{-3}$. This criterion as well as the node spacings of $\Delta r=0.025$ and $\Delta \phi=\pi / 18$ were chosen based on many trials and also by comparison of the results with those available in the literature for no rigid matrix present $(\gamma=0)$ as given in ref. [11] and those based on the exclusion of inertia, boundary and velocity square terms $(\operatorname{Pr} \rightarrow \propto, R a \rightarrow \infty$ and $\Psi=0)$ as given in refs. [6-8]. The quantities used in the comparison with the available results were $\psi, T$ and the average Nusselt number. The results for the comparison of the average Nusselt number for Darcy's regime are given in Figs. 5 and 6 and will be discussed later. In all cases agreements were found with the results of $[6-8,11]$.

In addition, for each run, an overall energy balance was made, i.e. the integrated heat transfer rate through the inner cylinder must be equal to that out of the outer cylinder. Agreements to less than $1 \%$ of the heat transfer rates were found.
The average normalized inner wall Nusselt number is defined as

$$
N u=-\frac{\ln R}{2 \pi} \int_{0}^{\pi} T_{r}(r=0.5) \mathrm{d} \phi
$$

where $2 / \ln R$ is the conduction Nusselt number.

\section{RESULTS AND DISCUSSION}

In spccial cascs equation (4) simplifies to the following forms

(a) $R a \rightarrow \infty, P r \rightarrow \infty, \Psi \rightarrow 0$ (i.e. Darcy's law)

$$
-\operatorname{Ra\gamma }^{-2}\left(r^{-1} \cos \phi T_{\phi}+\sin \phi T_{r}\right)-\omega=0 \text {. }
$$

(b) $R a \rightarrow \infty, \operatorname{Pr} \rightarrow \infty$ (i.e. insignificant inertial force and shear stresses)

$$
\begin{aligned}
& \operatorname{Ra\gamma }^{-2}\left(r^{-1} \cos \phi T_{\phi} \mid \sin \phi T_{r}\right) \cdots \omega \\
& +\Psi \gamma^{-2}\left[r^{-1}\left(r|\mathbf{u}| \psi_{r}\right)_{r}\right. \\
& \left.+r^{-2}\left(|\mathbf{u}| \psi_{\phi}\right)_{\phi}\right]=0 .
\end{aligned}
$$

(c) $\operatorname{Pr} \rightarrow \infty$ (i.e. insignificant inertial effects)

$$
\begin{gathered}
\gamma^{-2} \nabla \omega \omega^{2}-R a \gamma^{-2}\left(r^{-1} \cos \phi T_{\phi}+\sin \phi T_{r}\right)-\omega \\
+\Psi \gamma^{-2}\left[r^{-1}\left(r|\mathbf{u}| \psi_{r}\right)\right. \\
\left.+r^{-2}\left(|\mathbf{u}| \psi_{\phi}\right)_{\phi}\right]=0
\end{gathered}
$$

Since we are interested in the net heat transfer rate between the cylinders, the results will be presented such that they demonstrate the effect of the inertia, boundary and velocity-square terms on the average inner wall Nusselt number, i.e. $N u=N u(R, \operatorname{Pr}, R a, \gamma, \Psi)$. All of these effects reduce the heat transfer rate, but their relative significance varies greatly. In this study two diameter ratios,

\begin{tabular}{|c|c|c|c|c|c|c|c|c|c|c|c|c|}
\hline \multirow[b]{2}{*}{$\begin{array}{l}\text { Fluid, } g \beta / v^{2} \\
\left(\mathrm{~m}^{-3} \mathrm{~K}^{-1}\right)\end{array}$} & \multirow[b]{2}{*}{$\begin{array}{l}\Delta T \\
(\mathbf{K})\end{array}$} & \multicolumn{5}{|c|}{ Geometry } & \multicolumn{4}{|c|}{ Dimensionless parameters } & \multirow[b]{2}{*}{$\operatorname{Ray}^{-2}$} & \multirow[b]{2}{*}{$\begin{array}{c}N u \\
N u(\Psi=0\end{array}$} \\
\hline & & $\begin{array}{c}D_{\mathrm{i}} \\
(\mathrm{m})\end{array}$ & $\varepsilon$ & $\underset{\left(\mathrm{m}^{2}\right)}{K}$ & $F^{*}$ & $R$ & $\operatorname{Pr} *$ & $R a$ & $\gamma^{2}$ & $\Psi$ & & \\
\hline $1.6 \times 10^{8}$ & $10^{2}$ & 0.05 & 0.9 & $\begin{array}{l}10^{-5} \\
10^{-8} \\
10^{-5} \\
10^{-8} \\
10^{-5} \\
10^{-8} \\
10^{-5} \\
10^{-8}\end{array}$ & 0.1 & $\begin{array}{l}2 \\
4\end{array}$ & 0.5 & $10^{6}$ & $\begin{array}{l}2 \times 10^{2} \\
2 \times 10^{5} \\
2 \times 10^{2} \\
2 \times 10^{5} \\
2 \times 10^{2} \\
2 \times 10^{5} \\
2 \times 10^{2} \\
2 \times 10^{5}\end{array}$ & $\begin{array}{l}1.3 \\
41 \\
1.3 \\
41 \\
6.4 \\
200 \\
6.4 \\
200\end{array}$ & $\begin{array}{c}5 \times 10^{3} \\
5 \\
5 \times 10^{3} \\
5 \\
5 \times 10^{3} \\
5 \\
5 \times 10^{3} \\
5\end{array}$ & $\begin{array}{l}1.0 \\
1.0 \\
0.90 \\
1.0 \\
0.94 \\
1.0 \\
0.81 \\
1.0\end{array}$ \\
\hline
\end{tabular}
namely $R=2$ and 4 , have been chosen. Table 1 gives examples of some porous media saturated with gases at near standard conditions [14]. The porous media are polyurethane foams and some of the values given are not encountered in practice and are given for appreciation of the order of magnitude for the

Table 1. The effect of the velocity-square term on the average inner wall Nusselt number, for some gas-saturated foams

* For some polyurethane foams saturated with gases. In general $k_{e}$ and $F$ change with $K . K=10^{-5} \mathrm{~m}^{2}$ and $F=0.5$ are given as examples of extreme cases and are not normally encountered. 


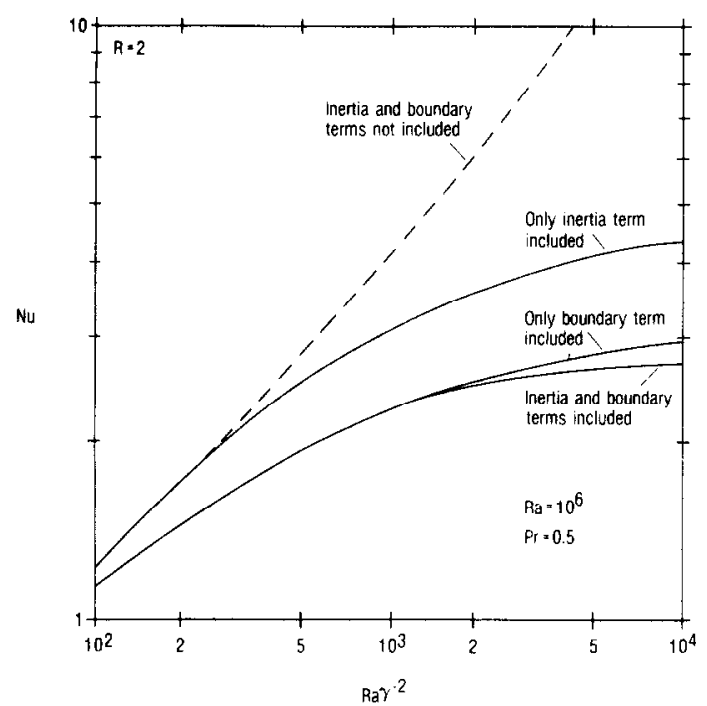

FIG. 2. The effect of inclusion of the inertia and boundary terms on the average inner wall Nusselt number. The results are for $R=2, R a=10^{6}, \operatorname{Pr}=0.5$ and various values of $\gamma^{2}$.

various dimensionless parameters. This table will be further examined in the section on the effect of the velocity-square term on the heat transfer rate.

Since a relatively comprehensive presentation of the variations in $\mathrm{Nu}$ with respect to each of the variables given above is rather lengthy, in the following some limited results are given with the objective of constructing flow regime diagrams where the regions of Darcy and non-Darcy convections can be identified.

\subsection{Inertia and boundary terms}

For a given relative buoyancy potential, as the permeability decreases the velocity decreases and the contribution of the inertia term to the overall force balance vanishes. A similar trend is expected for the shear-stress term. Figure 2 shows the variation in the average inner wall Nusselt number with the permeability for a given $R, R a$ and $P r$. The inertia effect is not significant at low permeabilities, $\dagger$ while the boundary effect persists to relatively lower permeabilities and generally dominates the inertia effects.

As shown in ref. [6], for the Darcy regime, as the value of $R a \gamma^{-2}$ increases the center of the cellular motion (one on each side) moves upward, i.e. above $\phi=\pi / 2$. Of course, this behavior is also observed when no rigid matrix is present (e.g. [11]). Since the Darcy's model does allow for velocity slip of the boundaries, it is expected that the inclusion of the boundary term would lower the center of the cell. Figure 3 shows the lines of constant temperature and streamfunction for $R a=10^{6}$ and $R a \gamma^{-2}=5 \times 10^{3}$. As expected, the boundary term causes the center of the circulation to move downward and also reduces the circulation (i.e. $\psi_{\max }$ ). The results for no boundary

† Note that $R a \gamma^{-2}=\left(g \beta v^{-1} \alpha_{\mathrm{e}}^{-1} \varepsilon^{-1} \Delta T D_{\mathrm{i}}\right) K$.

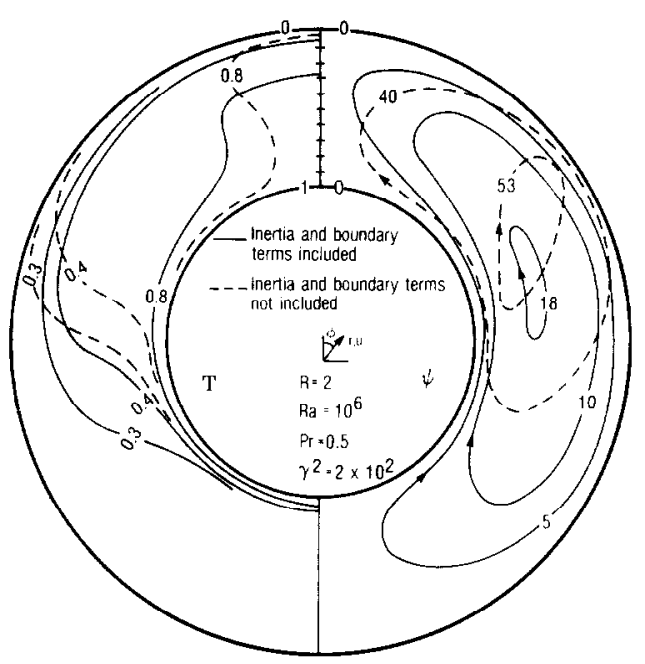

FIG. 3. The effect of inclusion of inertia and boundary terms on lines of constant streamfunction and temperature. The results are for $R=2, \operatorname{Ra}=10^{6}, \operatorname{Pr}=0.5$ and $\gamma^{2}=2 \times 10^{2}$.

term are in agreement with the trend found in ref. [6] for $R=2$. In ref. [6] the results are given for the values of $R a \gamma^{-2}$ equal to 40 and 400 (Figs. 4 and 7 in [6]). Note that as shown in Fig. 3 and found in ref. [6], for large values of $R a \gamma^{-2}$, the upward flow near the center of the cell is nearly vertical.

\subsection{Prandtl number}

The case of $\operatorname{Pr} \rightarrow \infty$ corresponds to no inertia effects. As $\operatorname{Pr}$ decreases, the effect of inertia increases. Figure 4 shows a further decrease in the Nusselt number with a decrease in the Prandtl number. Also when the conduction regime is approached, the results are independent of Prandtl number.

\subsection{Rayleigh number}

When both the buoyancy term and the first-order rigid matrix resistance term dominate over the other

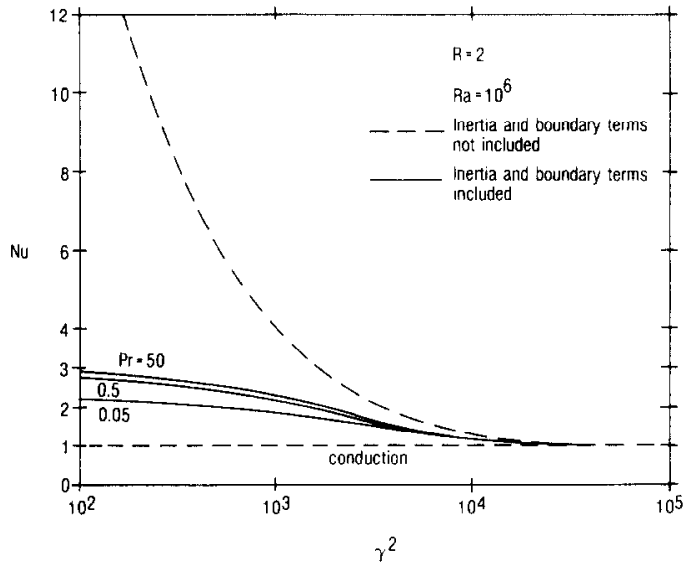

Fig. 4. The effects of the Prandtl number on the average inner wall Nusselt number for $R=2, R a=10^{6}$ and various values of $\gamma^{2}$ 


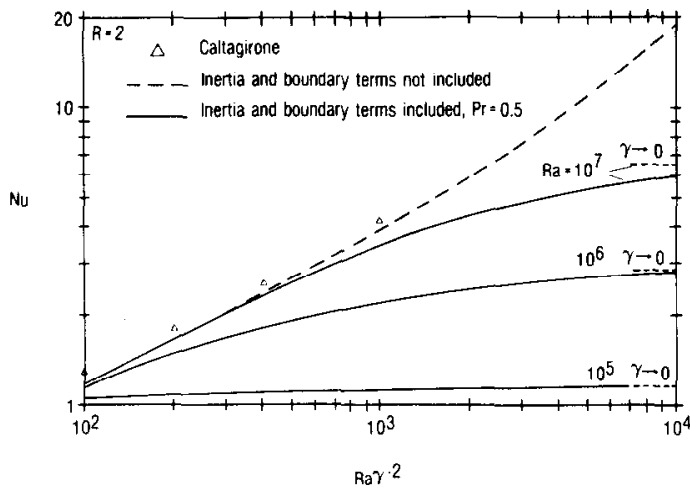

FIG. 5. The effect of inclusion of the inertia and boundary terms on the average inner wall Nusselt number for $R=2$, $P r=0.5$ and various values of $R a$. The numerical results of Caltagirone for no inertia and boundary effects are also given.

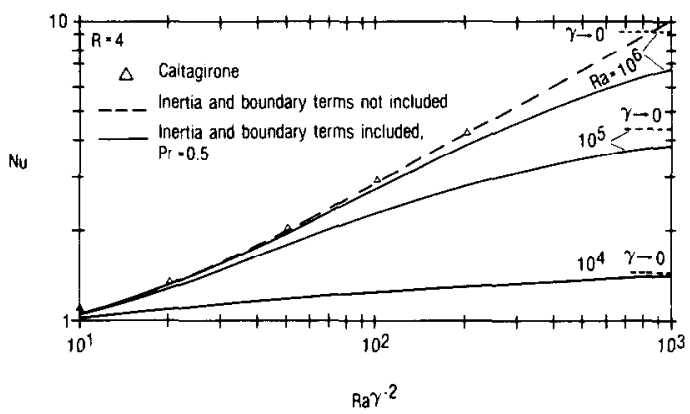

FIG. 6. The effect of inclusion of the inertia and boundary terms on the average inner wall Nusselt number for $R=4$, $P r=0.5$ and various values of $R a$. The numerical results of Caltagirone for no inertia and boundary effects are also given.

terms, Darcy's law holds. This corresponds to a boundary-layer type flow. Therefore, Darcy's model is valid for high Rayleigh numbers. This is shown in Fig. 5 (for $R=2$ ) where the increase in Rayleigh number, for a given $R a \gamma^{-2}$, results in vanishing inertia and boundary effects.

Based on the results given in Fig. 5, we note that in order to determine the regime of significant boundary and inertia effects, in addition to $R a \gamma^{-2}$ the value of $R a$ should also be considered. Figure 6 shows similar results for $R=4$. For this diameter ratio, $\nmid$ for a given $R a \gamma^{-2}$ the Nusselt number is larger than that for $R=2$. This is due to the increase in the circulation strength which confines the boundary effects to a small distance from the walls. As $R a$ increases, this boundary layer becomes thinner and the 'velocity jump' characteristic of Darcy's model, is approached.

In Figs. 5 and 6 the tabulated numerical results of ref. [6] are also shown and the agreement with the present results is good.

† Note that the Nusselt and Rayleigh numbers are based on $D_{\mathrm{i}}$.

\subsection{Velocity-square term}

Since the velocity-square term contains the permeability, its magnitude must be changed in accordance with $\gamma^{2}$. Table 1 gives a range for $\Psi$ characteristic of foams saturated with gases at near standard conditions [14]. The reduction in the Nusselt number, due to this term, is only significant when: (a) $R a \gamma^{-2}$ is large (due to large $R a$ and high $K$ ), which results in high velocities; and (b) $F$ is large. The maximum reduction in the Nusselt number, for the media considered, is about $20 \%$. In general this term does not contribute significantly to the reduction of the Nusselt number.

\subsection{Flow regimes}

Since for low permeability media the inertia term is insignificant, the Prandtl number effect can be neglected. Also, the velocity-square term is significant only when the boundary term is significant. Therefore, the boundary between regimes of Darcy and nonDarcy flow can be determined by only specifying $R a$ and $\gamma^{2}$. Although the transition from Darcian to nonDarcian regime is not absolute, we have taken any difference less than a few percent in $\mathrm{Nu}$ between the results based on the inclusion of all terms and exclusion of them, to indicate that the effects are negligible (Darcian convection). This is done in Fig. 7 for $R=2$ and 4 . As expected, pseudo-conduction regime persists up to higher $R a \gamma^{-2}$ for $R=2$.

The results show that

(a) along a line of constant $K$ (or $\gamma^{2}$ ), as $\Delta T$ (or $R a$ ) increases the conduction regime, Darcy regime and non-Darcy regime are encountered; and

(b) along a line of constant $R a \gamma^{-2}$ (or $\Delta T K$ ), as $R a$ (or $\Delta T$ ) increases the non-Darcy effect becomes less significant.

It is desirable to examine the experimental results of ref. [6] for $R=2$ (where glass beads and water were used) which have been shown to be in good agreement with the predictions based on Darcy's model.

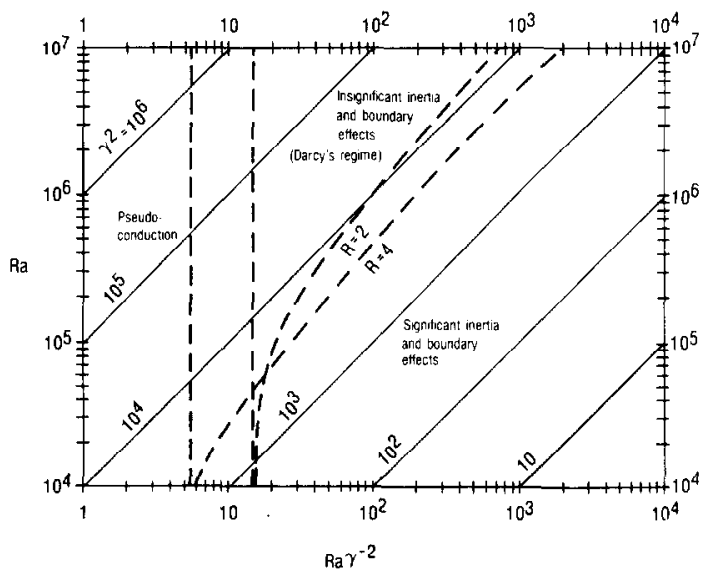

Fig. 7. The regimes of significant inertia and boundary effects for $R=2$ and 4 . 
Unfortunately, not all the necessary experimental conditions needed for evaluation of $R a$ are given in ref. [6]. However, if we estimate the effective Prandtl number to be about 3.0 [15] and also assuming that data for $R a \gamma^{-2}=6$ in the experiments of ref. [6] is for $T_{\mathrm{i}}-T_{\mathrm{o}}=10^{\circ} \mathrm{C}$, then we have $3 \times 10^{6}<R a<3 \times 10^{8}$. Now, examination of Fig. 7 shows that, as expected, the experimental results of ref. [6] are for high Rayleigh numbers and, therefore, are in Darcy's regime.

\section{SUMMARY}

Based on a semi-empirical momentum equation [1], which does not include the dispersion due to the inter-pore mixing in the presence of velocity gradients, the effects of inertia, boundary and velocity square terms on the heat transfer rate between two isothermal horizontal cylinders filled by a saturated porous medium is studied numerically. The results show that

(i) all of these effects reduce the heat transfer rate with the boundary effect being the most significant;

(ii) since at high values of $R a$, the flow becomes nearly of boundary-layer type, then for small values of $F$ Darcy's law holds when $R a$ and $P r$ both become very large; and

(iii) for a given $R$, the boundary between the Darcy and non-Darcy regimes is given by $R a \gamma^{-2}$ and $R a$. The flow regime diagrams for $R=2$ and 4 are determined.

\section{REFERENCES}

1. K. Vafai and C.-L. Tien, Boundary and inertia effects on convective heat transfer in porous media, Int. J. Heat Mass Transfer 34, 195-203 (1981),

2. M. Kaviany, Laminar flow through a porous channel bounded by isothermal parallel plates, Int. J. Heat Mass Transfer 28, 851-858 (1985).

3. P. Ranganathan and R. Viskanta, Mixed convective boundary layer flow along a vertical surface in a porous medium, Numer. Heat Transfer 7, 319-341 (1984).

4. J. T. Hong, C.-L. Tien and M. Kaviany, Non-Darcian effects on vertical plate natural convection in porous media with high porosity, Int. J. Heat Mass Transfer 28 2149-2157 (1985)

5. C. Bcaver and E. Sparrow, Non-Darcy flow through porous media, $J$. appl. Mech. 36, $711-714$ (1969).

6. J.-P. Caltagirone, Thermo-convective instabilities in a porous medium bounded by two concentric horizontal cylinders, J. Fluid Mech. 76, 337-362 (1976).

7. P. Burns and C. L. Tien, Natural convection in porous media bounded by concentric spheres and horizontal cylinders, Int. J. Heat Mass Transfer 22, 929-939 (1979).

8. G. Facas and B. Farouk, Transient and steady-state natural convection in a porous medium between two concentric cylinders, $J$. Heat Transfer 105, 660-663 (1983).

9. H. Bau, Low Rayleigh number thermal convection in a saturated porous medium bounded by two horizontal, eccentric cylinders, J. Heat Transfer 106, 166-175 (1984)

10. R. Powe, C. Carely and E. Bishop, Free convective flow patterns in cylindrical annuli, $J$. Heat Transfer 91 310-314 (1969).

11. T. Kuehn and R. Goldstein, An experimental and theoretical study of natural convection in the annulus between horizontal concentric cylinders, $J$. Fluid Mech. 74, 695-719 (1976).

12. M. Kaviany, Gradient destruction in flow through a rigid matrix, J. Fluid Mech. 165, $221-230$ (1986).

13. S. Patankar, Numerical Heat Transfer and Fluid Flow. Hemisphere, Washington, DC (1980).

14. W. M. Kays and M. E. Crawford, Convective Heat and Mass Transfer, pp. 388-391. McGraw-Hill, New York (1980),

15. M. Kaviany, Onset of thermal convection in a saturated porous medium: experiment and analysis, Int. J. Heat Mass Transfer 27, 2101-2110 (1984).

\title{
EFFETS NON DARCIENS SUR LA CONVECTION NATURELLE DANS LES MILIEUX POREUX CONFINES ENTRE DES CYLINDRES HORIZONTAUX
}

\begin{abstract}
Résumé-Les termes d'inertie, de frontière et de carré de vitesse, normalement ignorés dans l'analyse de l'écoulement sont inclus dans l'étude de la convection naturelle entre des cylindres isothermes, concentriques (cylindre intérieur chaud), avec remplissage par un milieu poreux saturé. Les résultats montrent que tous ces effets réduisent le transfert de chaleur, le terme de frontière étant le plus important. On montre que puisque, aux grands nombres de Reynolds, l'écoulement adjacent aux parois devient du type couche limite avec une très fine sous-couche au-delà de laquelle la vitesse atteint son maximum, aussi longtemps que la contribution du terme de carré de vitesse est faible, le modèle de Darcy est valable pour de très grands nombres de Rayleigh et de Prandtl. On donne un diagramme montrant les régimes de pseudo-conduction, de Darcy et de non Darcy.
\end{abstract}

\section{NICHT-DARCY-EFFEKTE BEI NATÜRLICHER KONVEKTION IN PORÖSEN MEDIEN ZWISCHEN ZWEI HORIZONTALEN ZYLINDERN}

Zusammenfassung-Die quadratischen Terme für Trägheit, Berandung und Geschwindigkeit, die normalerweise in der Strömungsanalyse nicht berücksichtigt sind, werden in die Untersuchung der natürlichen Konvektion zwischen isothermen konzentrischen Zylindern (innerer Zylinder beheizt), bei denen der Spalt mit einem gesättigten porösen Medium gefült ist, einbezogen. Die Ergebnisse zeigen, daB all diese Effekte den Wärmetransport behindern, wobei der Term für die Berandung der bedeutendste ist. Es zeigt sich, daß bei hohen Rayleigh-Zahlen die Strömung an den Zylinderwänden vom Typ einer Grenzschichtströmung mit einer sehr dünnen Unterschicht ist, oberhalb der die Geschwindigkeit maximal wird. Solange der Beitrag des quadratischen Geschwindigkeitsterms klein ist, gilt deshalb Darcy's Modell für sehr große Rayleigh- und Prandtl-Zahlen. Ein Diagramm der Strömungsbereiche zeigt Gebiete der PseudoWärmeleitung, auBerdem Darcy- und Nicht-Darcy-Gebiete. 


\section{ИССЛЕДОВАНИЕ ВЛИЯНИЯ ЭФФЕКТОВ, НЕ ПОДЧИНЯЮЩИХСЯ ЗАКОНУ ДАРСИ, НА ЕСТЕСТВЕННУЮ КОНВЕКЦИЮ В ЗАКЛЮЧЕННОЙ МЕЖДУ ДВУМЯ ГОРИЗОНТАЛЬНЫМИ ЦИЛИНДРАМИ ПОРИСТОЙ СРЕДЕ}

Аннотаци-Проведено исследование естественной конвекции между изотермическими концентрическими заполненными насыпценной пористой средой цилиндрами (внутренний цилиндр нагрет) с учетом влияния инерционных сил, граничных условнй и процессов, описываемых квадратичными по скорости членами, что обычно не делалось ранее. В результате получено меньшее значение плотности теплового потока, на которую больше всего влияют условия на границе. В силу того, что при больших значениях числа Рэлея поток вблизи ограничивающих стенок приобретает характер течения в пограничном слое, в котором возможна максимальная скорость в пределах очень тонкого подслоя, показано, что модель Дарси можно использовать при очень болыших числах Рэлея и Прандтля только в том случае, пока влияние процессов, описываемых квадратичными по скорости членами, незначительно. Приведена диаграмма течений, иллюстрирующая наличие псевдорежима Дарси и режима, не подчиняющегося закону Дарси. 